\title{
Microstructural Evolution and Mechanical Behavior of Friction-Stir-Welded DP1180 Advanced Ultrahigh Strength Steel
}

\author{
Z. W. Wang ${ }^{1,2} \cdot$ G. M. Xie ${ }^{3}$ D. Wang ${ }^{1} \cdot$ H. Zhang ${ }^{1} \cdot$ D. R. $\mathrm{Ni}^{1} \cdot$ P. Xue ${ }^{1}$ - B. L. Xiao ${ }^{1} \cdot$ Z. Y. Ma ${ }^{1}$
}

Received: 23 May 2019 / Revised: 9 July 2019 / Published online: 10 October 2019

(C) The Chinese Society for Metals (CSM) and Springer-Verlag GmbH Germany, part of Springer Nature 2019

\begin{abstract}
Friction stir lap welding of a DP1180 advanced ultrahigh strength steel was successfully carried out by using three welding tools with different pin lengths. The effects of the welding heat input and material flow on the microstructure evolution of the joints were analyzed in detail. The relationship between pin length and mechanical properties of lap joints was studied. The results showed that the peak temperatures of all joints exceeded $A_{\mathrm{c} 3}$, and martensite phases with similar morphologies were formed in the stir zones. These martensite retained good toughness due to the self-tempering effect. The formation of ferrite and tempered martensite was the main reason for the hardness reduction in heat-affected zone. The mechanical properties of the lap joints were determined by loading mode, features of lap interface and the joint defects. When the stir pin was inserted into the lower sheet with a depth of $0.4 \mathrm{~mm}$, the lap joint exhibited the maximum tensile strength of $12.4 \mathrm{kN}$.
\end{abstract}

Keywords Advanced ultrahigh strength steel $\cdot$ Friction stir welding $\cdot$ Microstructure $\cdot$ Mechanical behavior

\section{Introduction}

Although various lightweight materials are constantly developed recently, steels are still main structural materials in automobile manufacturing. In recent years, advanced ultrahigh strength steels (AUHSSs) with tensile strength over $1 \mathrm{GPa}$ are required to achieve weight reduction, energy saving and improvement in vehicle body safety $[1,2]$.

For AUHSS, heat treatment and plastic deformation are usually used to achieve desirable microstructure. Therefore, AUHSS usually contains fine grains and metastable phases

Available online at http://link.springer.com/journal/40195

H. Zhang

haozhang@imr.ac.cn

$\triangle$ P. Xue

pxue@imr.ac.cn

1 Shenyang National Laboratory for Materials Science, Institute of Metal Research, Chinese Academy of Sciences, Shenyang 110016, China

2 School of Materials Science and Engineering, University of Science and Technology of China, Shenyang 110016, China

3 State Key Laboratory of Rolling and Automation, Northeastern University, Shenyang 110819, China (such as martensite, bainite and retained austenite) [3, 4]. Thus, AUHSS is often in a condition of high-energy metastable state, and its unstable structures are very sensitive to the cyclic heat during welding. For instance, the martensite in dual-phase (DP) steels can easily loss its hardness with carbide precipitation during tempering, even if it underwent a temperature far below the $A_{\mathrm{c} 1}$ phase transition temperature. Therefore, achieving high quality AUHSS joints with good mechanical properties has been a great challenge [5]. At present, the sharp decline in weldability has become a key factor hindering the wide application of AUHSS.

Nowadays, fusion welding techniques like laser welding (LW) and resistance spot welding (RSW) have been successfully applied in the auto-body manufacturing. Nevertheless, there are still some disadvantages for the fusion welding of AUHSS. Firstly, the melting process completely destroys the original structures of AUHSS, and it is easy to form brittle microstructure with high strain in the weld zone which can reduce the joint toughness significantly [6,7]. Secondly, solidification-related defects like voids and cracks can be formed during the fusion process $[8,9]$. Thirdly, AUHSS is more sensitive to thermal cycle than traditional low-strength carbon steels. Thus, serious decrease in the joining properties can be observed in its fusion-welded joint.

Friction stir welding (FSW), a kind of advanced solid-state welding technique with relatively low heat input $[10,11]$, has 
been successfully applied to the joining of aluminum and magnesium alloys [12-15]. With the continuous development of welding tools, FSW has gradually demonstrated its merits in the welding of high melting point materials such as steels, titanium alloys and superalloys [16-19]. Because of the absence of melting during welding, FSW can ameliorate the problems in fusion welding and has shown great possibility of joining AUHSSs.

At present, the investigations on the microstructure and mechanical performance of AUHSS FSW joints are still scanty. Ghosh et al. [20, 21] successfully performed FSW on ultrahigh strength martensitic steel with lap joint under high heat input parameter (rotation rate of $1000 \mathrm{rpm}$ ). They found that two heat-affected zones (HAZs) were formed in the joint due to the variety of the temperature field. The HAZ2 was away from the stir zone (SZ) and exhibited mixed structures of ferrite and pearlite, which was the lowest hardness zone with the hardness of only $40 \%$ of the parent metal (PM).

Mironov et al. [22] achieved FSW joint of a 1.2 GPa transformation-induced plasticity (TRIP) steel. Hard quenched martensite was produced in the SZ, and the HAZ softening was mainly related to the reduced fraction of retained austenite and decomposition of bainite. In addition, ultrahigh strength twinning-induced plasticity (TWIP) steel was also successfully welded [23]. Grain growth, the dissolution and coarsening of nano-precipitated VC, led to the softening in the HAZ.

Matsushita et al. [24] obtained defect-free butt joint of HT1180 DP steel. It was revealed that the peak temperature during welding could reach $900{ }^{\circ} \mathrm{C}$ at a rotation rate of $400 \mathrm{rpm}$. Hard and brittle martensite and bainite phases generated in the SZ. The HAZ softening was serious and the minimum Vickers hardness was about $70 \%$ of the PM. The microstructural evolution of the joint exerted a crucial effect on the mechanical properties of the joint.

The above works provided a preliminary understanding of the effects of FSW on the microstructure and properties of AUHSSs. Diverse softening mechanisms of the HAZ were found for different steels. Nevertheless, significant aspects of joint microstructural evolution, including the efficacy loss of strengthening phase as well as mechanisms of the phase transformations during different temperature regions, still lack deep understanding. This obstructs clearly cognition to the HAZ softening mechanisms.

In the current work, lap FSW was performed on ultrahigh strength DP steel to provide deeper insight into these issues. It should be noted that the lap joint rather than butt joint was adopted here considering the future industrial application and welding feasibility. The evolution of joint microstructures was also concerned to evaluate the FSW heat effect on ultrahigh strength DP steel.

\section{Experimental}

Commercial DP1180 steel sheets (ultimate tensile strength of $1250 \mathrm{MPa}$ ) with thickness of $1.35 \mathrm{~mm}$ were used. The chemical composition is summarized in Table 1 . Two sheets were lap-welded, and the argon shielding was employed to prevent oxidation of the weld surface. W-Re alloy FSW tool which consisted of a concave shoulder with a diameter of $11 \mathrm{~mm}$ and a tapered pin with a root diameter of $5 \mathrm{~mm}$ was used. During the welding process, the stir tool was tilted with $3^{\circ}$ relative to the vertical direction. An optimized parameter combination of $400 \mathrm{rpm}, 150 \mathrm{~mm} / \mathrm{min}$ and $0.18 \mathrm{~mm}$ for the tool rotation rate $(\omega)$, welding speed $(\nu)$ and the shoulder plunge depth $(D)$ was chosen, respectively. In this study, the inserted depth of stir pin into the lower sheet $(d)$ was appointed as the reference variable to analyze the effect of the pin length $(l)$ on the joint morphology, microstructure and properties. The required three types of pin length were calculated according to the thickness of the sheet and are listed in Table 2.

The schematic diagrams of FSW processes are shown in Fig. 1. Two welding forms were adopted according to different loading modes of the joints during the tensile test. They are the advancing side loaded in the upper sheet (abbreviated as AS-loaded) shown in Fig. 1a and the retreating side loaded in the upper sheet (abbreviated as RS-loaded) shown in Fig. 1b. After welding, the joints were cut into tensile shear specimens with $10 \mathrm{~mm}$ in width by wire electric discharge machine along the transverse direction (TD). Three parallel samples were prepared for each parameter, and the tensile tests were conducted at a speed of $1 \mathrm{~mm} / \mathrm{min}$.

Microstructures of joints were characterized by optical microscopy (OM) and scanning electron microscopy (SEM).

Table 2 Experimental welding parameters

\begin{tabular}{lllll}
\hline$d(\mathrm{~mm})$ & $\omega(\mathrm{rpm})$ & $\nu(\mathrm{mm} / \mathrm{min})$ & $D(\mathrm{~mm})$ & $l(\mathrm{~mm})$ \\
\hline 0.2 & & & & 1.37 \\
0.4 & 400 & 150 & 0.18 & 1.57 \\
0.8 & & & & 1.97 \\
\hline
\end{tabular}

$d$ inserted depth of stir pin into lower sheet, $\omega$ rotation rate, $\nu$ welding speed, $D$ inserted depth of shoulder into upper sheet, $l$ length of stir pin
Table 1 Chemical composition of DP1180 steel (wt\%)

\begin{tabular}{llllllllll}
\hline $\mathrm{C}$ & $\mathrm{Mn}$ & $\mathrm{Si}$ & $\mathrm{Cr}$ & $\mathrm{Mo}$ & $\mathrm{Cu}$ & $\mathrm{Al}$ & $\mathrm{S}$ & $\mathrm{P}$ & $\mathrm{Fe}$ \\
\hline 0.18 & 2.4 & 0.60 & 0.02 & 0.01 & 0.02 & 0.05 & 0.005 & 0.01 & Bal. \\
\hline
\end{tabular}



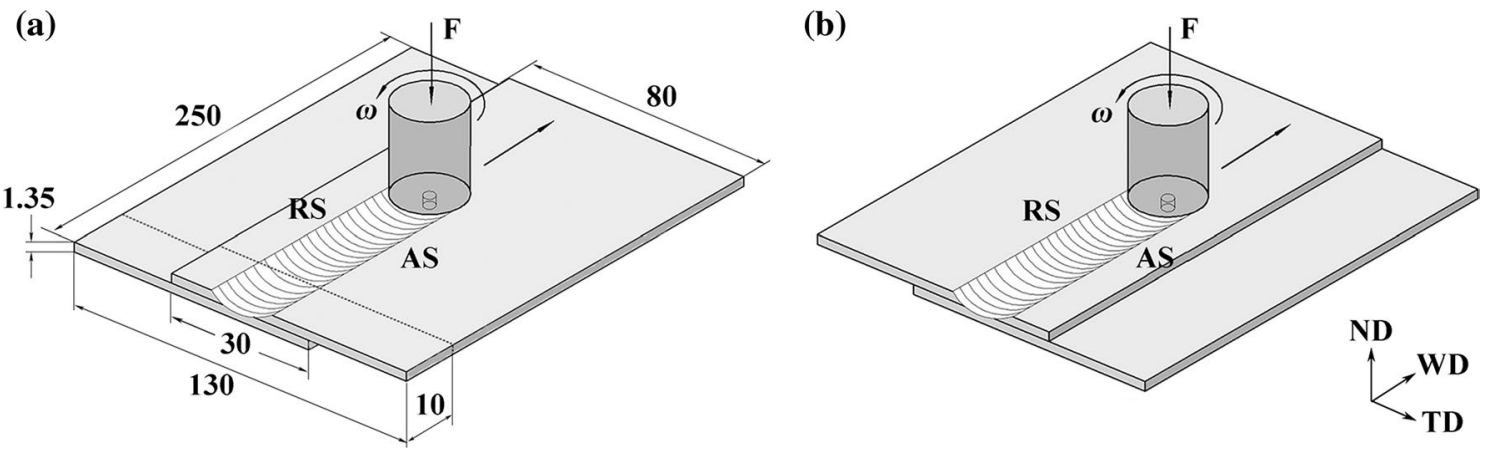

Fig. 1 Schematic diagrams of two kinds of FSW processes: a AS-loaded, b RS-loaded

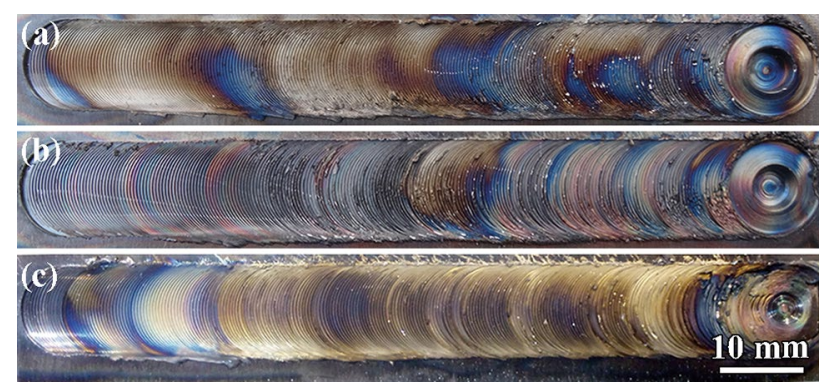

Fig. 2 Surface morphologies of FSW joints at different inserted depths of the stir pin: a $0.2 \mathrm{~mm}$, b $0.4 \mathrm{~mm}$ and c $0.8 \mathrm{~mm}$

The metallographic analysis was undertaken at the cross section perpendicular to the welding direction (WD). The samples were polished and then etched with 5\% nitric acid. The Vickers hardness measurement was performed on the joint cross section along the center thickness of the upper sheet (TD) and the center of the weld (normal direction, ND) with a distance of $1 \mathrm{~mm}$ and $0.3 \mathrm{~mm}$ between adjacent points, respectively. During the hardness test, a load of $200 \mathrm{~g}$ with a dwell time of $15 \mathrm{~s}$ was used.

\section{Results}

\subsection{Joint Morphologies}

Defect-free weld surfaces were well formed when the inserted depth was $0.2 \mathrm{~mm}$ (Fig. 2a) and $0.4 \mathrm{~mm}$ (Fig. 2b). When the inserted depth was increased to $0.8 \mathrm{~mm}$ (Fig. 2c), the material in the rear weld was slightly piled on the surface and thickened, and intermittent veins were formed. Typical SZ, HAZ and the PM were observed in the cross-sectional morphologies of the joints shown in Fig. 3. The conventional thermal-mechanical zone (TMAZ) was hard to detect here for the insufficient material flow and phase transformation of AUHSS. Similar phenomenon was found in the research of Khodir et al. [25] on FSW of high carbon steel. Small hook defect at the interface could be found between the upper and lower sheets on the AS (Fig. 3c, e), while the cold lap defect was generally formed in the weld center or near the RS. When $0.2 \mathrm{~mm}$ was selected for the inserted depth (Fig. 3a, d), the most serious cold lap was found throughout the SZ. When the inserted depth was $0.8 \mathrm{~mm}$, obvious voids could be observed in the bottom of the SZ as shown in Fig. 3c.
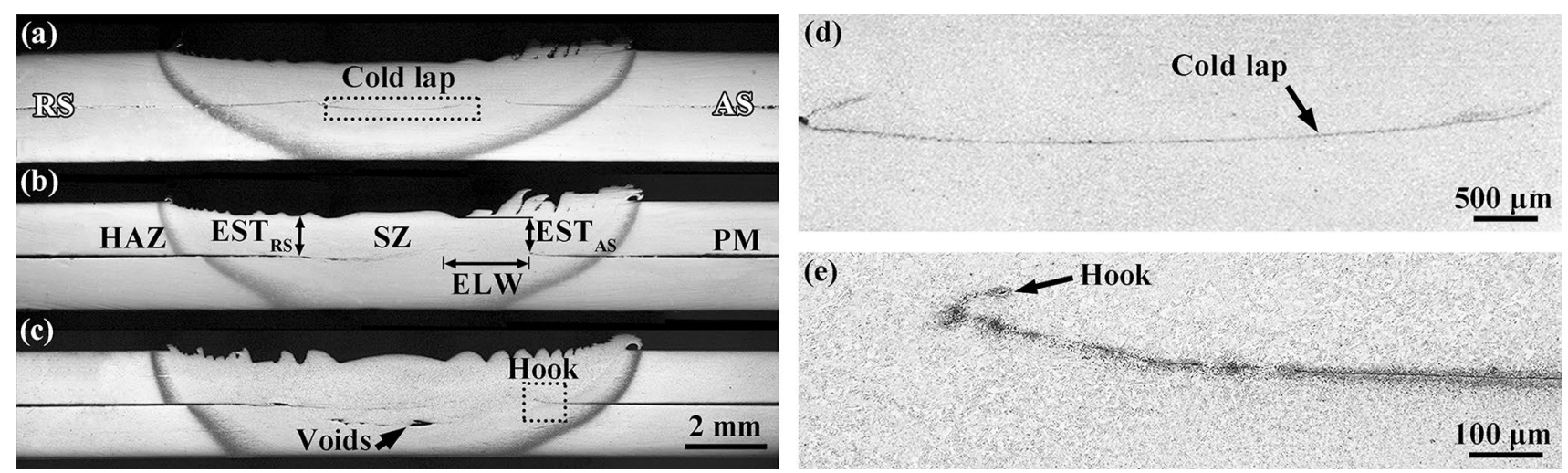

Fig. 3 Cross-sectional OM macrographs of FSW joints at different inserted depths of the stir pin: a, d $0.2 \mathrm{~mm}, \mathbf{b} 0.4 \mathrm{~mm}, \mathbf{c}, \mathbf{e} 0.8 \mathrm{~mm}$ 


\subsection{Microstructures of Joints}

Figure 4 shows the SEM morphologies of the joint with $0.4 \mathrm{~mm}$ inserted depth (the observing position is near the AS of the upper sheet). It can be seen from Fig. $4 \mathrm{~b}$ that the PM contained typical dual-phase structures of ferrite $(F)$ and martensite (M) after inter-critical quenching and plastic deformation [26]. A small number of ferrite with obvious rolling deformation characteristic could be observed. The prior austenite grain boundary surrounding martensite could be readily distinguished with grain sizes below $5 \mu \mathrm{m}$.

Figure $4 \mathrm{c}$ shows that lath martensite was produced in the SZ and exhibited typical tempered morphology. Large numbers of fine carbide particles could be observed within martensite. The macrostructure of Fig. 4a manifested that the HAZ far from the SZ could be divided into three subregions: HAZ1 (Fig. 4d), HAZ2 (Fig. 4e) and HAZ3 (Fig. 4f). Although the grain size of each subregion was similar to that of the PM, obvious differences in morphology could be observed. Similar subregions with intricate microstructural evolution were also found in laser-welded martensite steel and DP980 steel joints, respectively [7, 27]. HAZ1 contained a small number of ferrite with a size of $1-2 \mu \mathrm{m}$ around the martensite. Meanwhile, the prior austenite also showed a small size of $2-3 \mu \mathrm{m}$ with a certain number of carbide particles. In HAZ2, the content of ferrite increased, and almost no carbide precipitated in the martensite which showed a morphology of quenched state. In HAZ3, many carbide particles were observed along the prior austenite grain boundaries, and laths of martensite with typical tempered morphology could be found. In addition, considering the microstructural features of the SZ with inserted depths of $0.2 \mathrm{~mm}$ and $0.8 \mathrm{~mm}$ (Fig. 5), the SZs in all joints had produced martensite with similar size. This indicated approximately the same peak temperature and microstructure evolution in the SZs during welding.

\subsection{Mechanical Properties}

The hardness distribution of $0.4 \mathrm{~mm}$ inserted depth joint is presented in Fig. 6. The hardness values of the SZ with an average value of $410 \mathrm{Hv}$ were slightly higher than those of the PM $(380 \mathrm{Hv})$. The minimum hardness point with the value of $280 \mathrm{Hv}$ was located at the boundary of HAZ2 and HAZ3, which was reduced by $26 \%$ compared to that of the PM. All the hardness of three SZs along the ND was similar and close to $410 \mathrm{Hv}$, which was coincident with the microstructural uniformity of the SZs.

Figure 7 shows the tensile shear results of the joints. Firstly, the average lap shear strength of the RS-loaded specimens was generally higher than that of the AS-loaded ones. Considering the fracture locations shown in Fig. 8, the strength of the AS-loaded specimens was mainly affected by the cold lap (0.2 AS-loaded) and hook defects (0.4

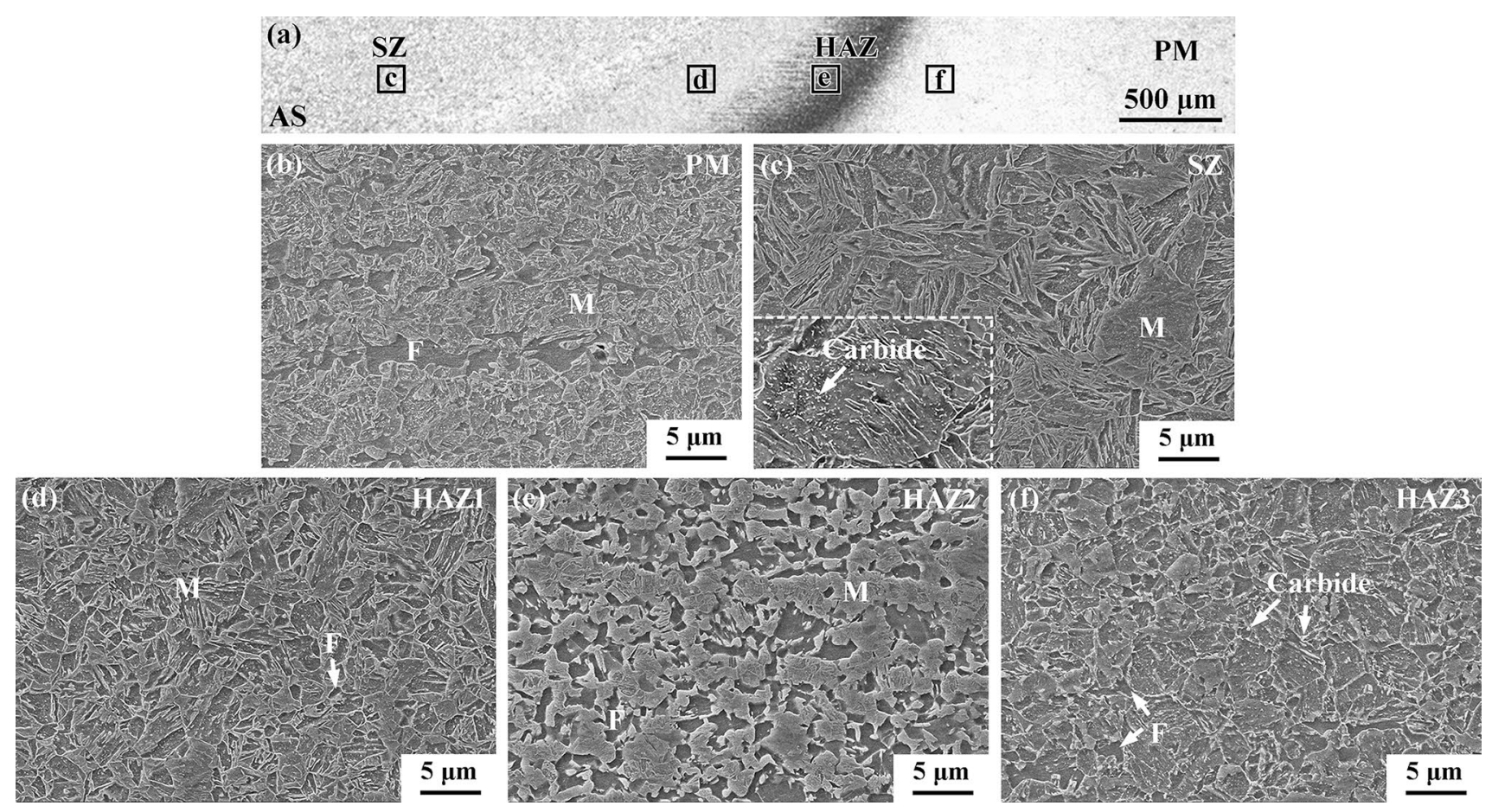

Fig. 4 OM and SEM images in different regions with a $0.4 \mathrm{~mm}$ inserted depth joint: a the top sheet on the AS, b PM, c SZ, d HAZ1, e HAZ2, f HAZ3 

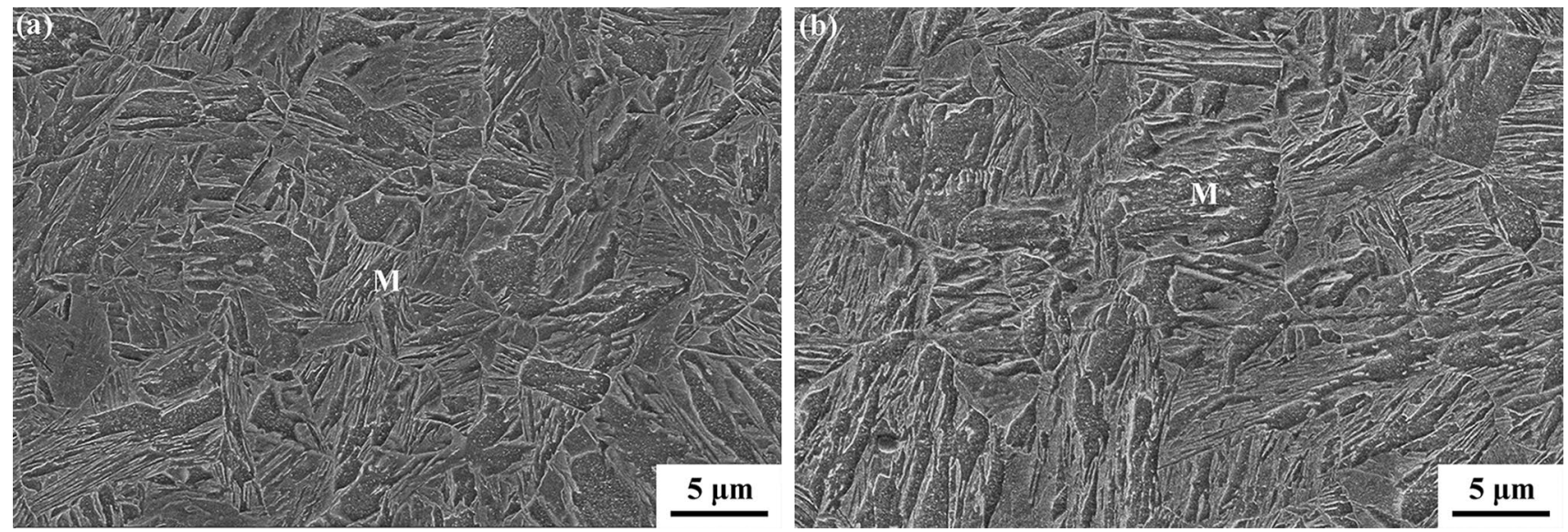

Fig. 5 SEM images showing the SZ microstructures at inserted depths of a $0.2 \mathrm{~mm}, \mathbf{b} 0.8 \mathrm{~mm}$

(a)

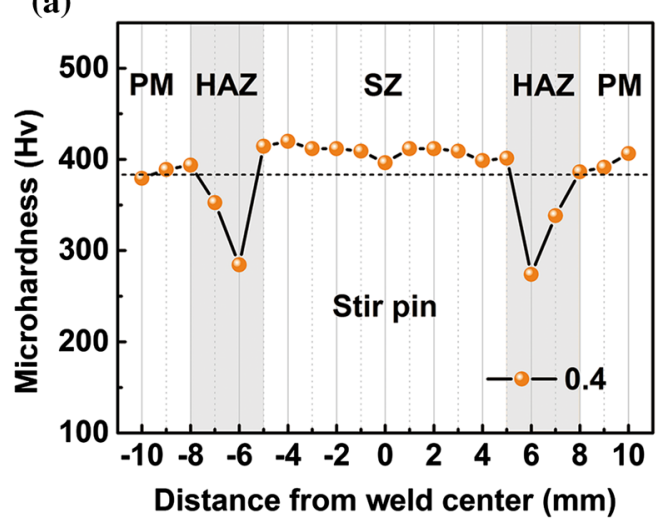

(b)

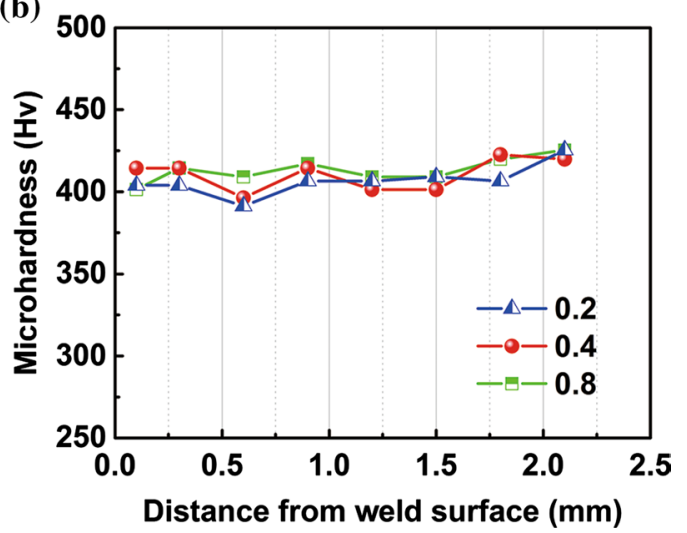

Fig. 6 Hardness distribution along a TD of $0.4 \mathrm{~mm}$ inserted depth joint, $\mathbf{b}$ ND of all joints with different inserted depths

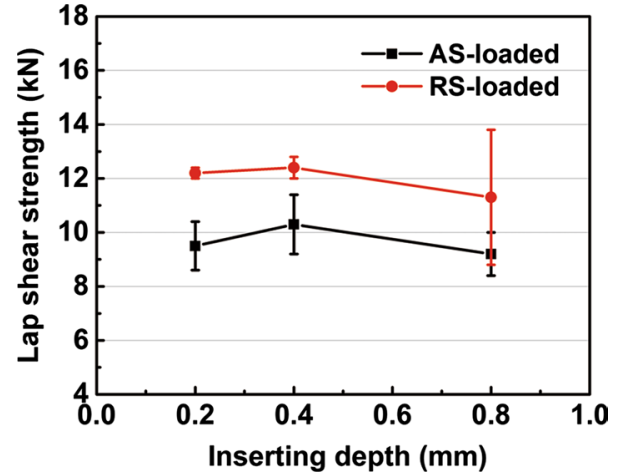

Fig. 7 Tensile shear properties of joints with different welding parameters

AS-loaded or 0.8 AS-loaded). Especially the 0.2 AS-loaded specimen cracked along the cold lap and finally failed at the interface between the two sheets. Secondly, for both two kinds of samples, their strength increased slightly and then gradually decreased with increasing inserted depth. The optimal lap shear strength of $12.4 \mathrm{kN}$ was obtained for the 0.4 RS-loaded specimen. When the inserted depth was increased to $0.8 \mathrm{~mm}$, low joining strength and significant deviation could be observed for the RS-loaded joint. The above phenomena were mainly related to the less welding defects of the $0.4 \mathrm{~mm}$ inserted depth joint, the formation of severe cold lap defect for $0.2 \mathrm{~mm}$ inserted depth joint and the inferior joint morphologies of $0.8 \mathrm{~mm}$ inserted depth joint. Moreover, taking both the microhardness distribution and fractural locations into consideration, it indicated that the failure modes were mainly dominated by the defect types and the loading forms of the joint.

As shown in Fig. 9, two types of fracture surface morphologies were found after the tensile test. One was shear fracture mode such as the 0.2 AS-loaded sample (Fig. 9a-c, and the observed direction is shown by the white arrow in Fig. 8a); and the other was the tensile fracture mode such as the 0.4 RS-loaded sample (Fig. 9d, and the observed direction is shown by the white arrow in Fig. 8e). For shear 

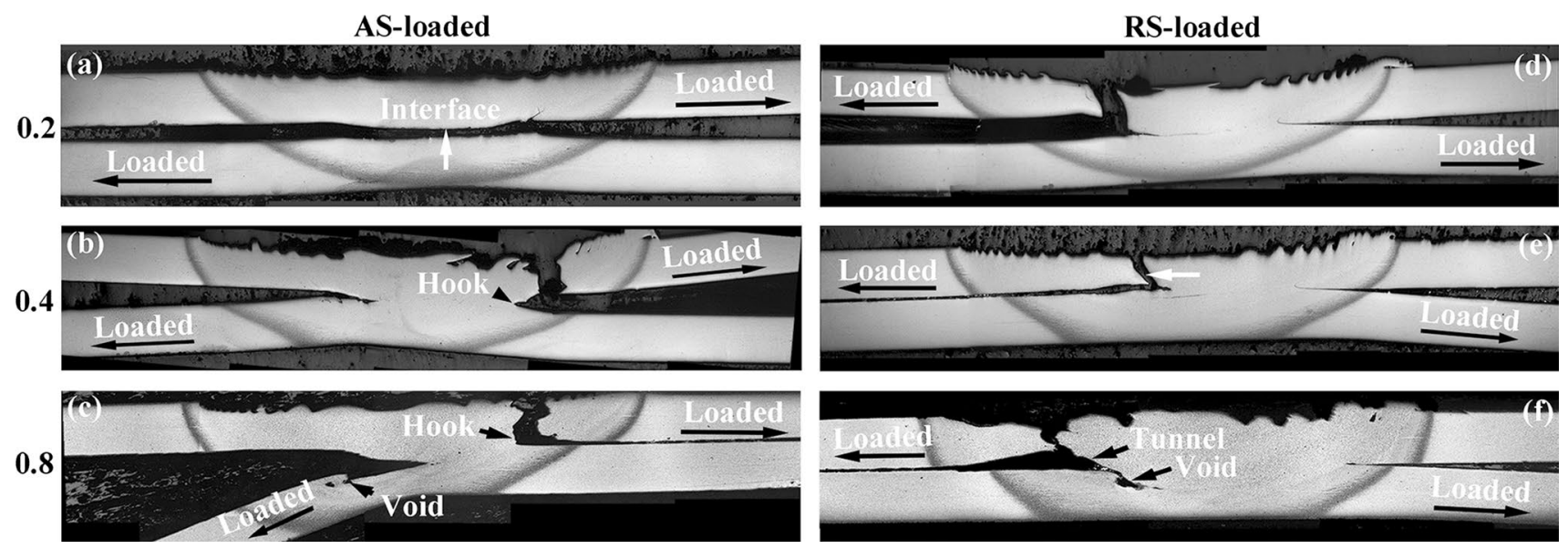

Fig. 8 OM images of fracture locations of tensile shear specimens with different welding parameters

fracture mode, the interfacial bonding mainly depended on the cold lap region (zone b in Fig. 9a) and the bonding region between hook and cold lap (zone c in Fig. 9a). The cold lap region generally showed weak metallurgical joining and small shallow dimple-like morphology with poor joining strength (as shown in Fig. 9b) [28]. Meanwhile, the bonding region exhibited flat laminar morphology as shown in Fig. 9c. This region mainly undertook shear strain caused by shear stress. For the tensile fracture mode, the fractured interface showed a large number of dimples under normal stress (Fig. 9d), indicating that tough martensite was obtained in the SZ.

\section{Discussion}

\subsection{Microstructural Evolution Under Gradient Temperature Field}

The $A_{\mathrm{c} 1}$ and $A_{\mathrm{c} 3}$ phase transformation temperatures of DP1180 steel were calculated to be $729^{\circ} \mathrm{C}$ and $820{ }^{\circ} \mathrm{C}$, respectively [29]. According to Figs. 4 and 5, the microstructure in the SZ was predominantly martensitic. That is, the peak temperature under present welding parameter was higher than $A_{\mathrm{c} 3}$, and the $\mathrm{SZ}$ was heated to the austenite field ( $\gamma$ phase field), as shown in Fig. 10. The single-phase austenite in this region underwent severe plastic deformation and recrystallization during the welding process and then rapidly cooled to room temperature and transformed into martensite. This agrees with the microstructural feature in the SZ during FSW of M190 steel [21]. In addition, due to the self-tempering effect of carbon steels during cooling [30], carbide particles could be observed in the martensite (Fig. 4c), which caused the inconspicuous enhancement of hardness in the SZ compared with that in the PM (Fig. 6a).
The HAZ was located in the region between PM and SZ and was inevitably affected by thermal cycle with lower peak temperature compared with the SZ. The cold-rolled PM had high storage energy. Therefore, recovery and recrystallization tended to take place at elevated temperature. As a result, different types of solid-state phase transformation might occur, leading to the heterogeneous hardness distribution in the HAZ. Among the three subregions of HAZ, it was believed that the HAZ1 (Fig. 4d) underwent temperature close to $A_{\mathrm{c} 3}$, due to the existence of a small number of fine ferrite in the martensite matrix. The martensite and ferrite in this subregion mainly underwent static recrystallization during the succedent ferrite-austenite transformation. These fine structures were retained due to the short residence time at high temperature during the FSW process. Whereafter, dual-phase structures with high hardness were maintained. Similar structural features have been reported in the investigations on quenching and partitioning steels and martensite steels, which was called inter-critical HAZ or fine-grain HAZ [31-33].

The peak temperature in HAZ2 was between $A_{\mathrm{c} 1}$ and $A_{\mathrm{c} 3}$ (the $\alpha+\gamma$ field in Fig. 10). Owing to less thermal influence, the self-tempering effect of the martensite was restricted and martensite without carbide was formed. In addition, large numbers of equiaxed ferrite were generated in HAZ2 due to insufficient recrystallization and austenitizing of ferrite under this temperature (Fig. 4e). Although the supersaturated martensite in this region was hard, the hardness gradually decreased to the minimum value with the increased proportion of soft ferrite in the two-phase structures (Fig. 6a).

For HAZ3, there was no significant change in the microstructure morphology compared with the PM. In this region, granular carbides along the martensite lath boundaries and the prior austenite boundaries could be found, which revealed that the peak temperature was below $A_{\mathrm{c} 1}$ and no phase transformation of ferrite occurred. This 

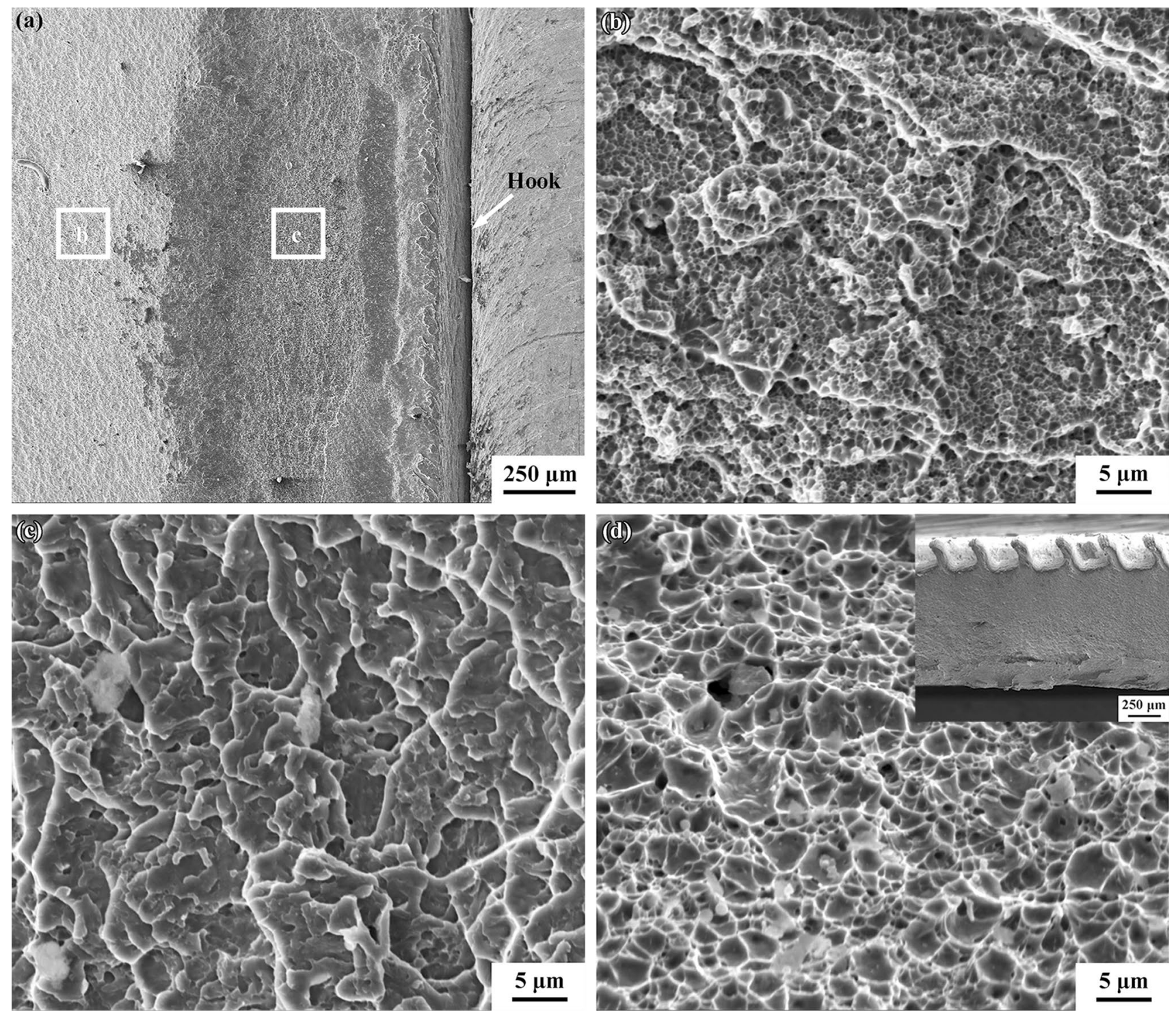

Fig. 9 SEM micrographs of the fracture surfaces of typical tensile shear specimens: a-c 0.2 AS-loaded, $\mathbf{d}$ 0.4 RS-loaded

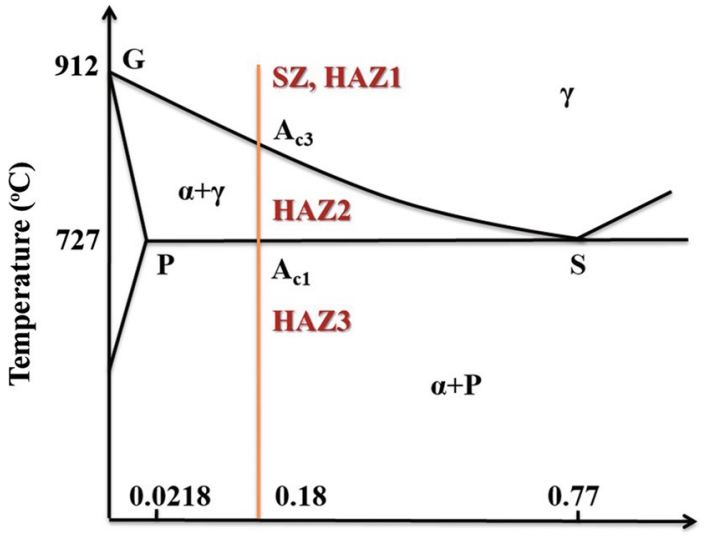

$\mathrm{C}(\mathbf{w t} \%)$

means uncompleted static recrystallization might occur in ferrite. Martensite mainly underwent the migration and segregation of carbon atoms and precipitation of carbides due to higher recrystallization temperature. The microhardness value gradually rose outwards from the weld center, and the relevant microstructural morphology was similar to the PM.

From the above analysis, the generation of the gradient temperature field during the welding process was the reason why the heterogeneous microstructural regions were formed. The recrystallization and phase transformation controlled structural characteristics in different joint regions. For example, the SZ undertook complete phase transformation. Complete recrystallization + phase transformation, incomplete recrystallization + phase transformation and

Fig. 10 Sketch phase diagram of $\mathrm{Fe}-\mathrm{Fe}_{3} \mathrm{C}$ 
incomplete recrystallization occurred in HAZ1, HAZ2 and HAZ3, respectively.

\subsection{Factors Affecting the Mechanical Properties of Joints}

(1) The influence of welding parameter

Essentially, the interfacial morphology can be influenced by adjusting the welding parameters. In general, the material flow in the horizontal direction mainly affects the effective lap width (ELW, as shown in Fig. 3b), which determines the fracture mode and joint strength [28]. The vertical material flow caused the forming of hook defect and changed the shape of the cold lap, which was strongly related to the effective sheet thickness (EST, as shown in Fig. 3b). The investigation on lap FSW of aluminum alloys reported by Li et al. [28, 34] shows that the ELW could be increased by increasing the rotation rate, but the EST was reduced simultaneously. Meanwhile, exorbitant traversing speed could also reduce the ELW. Therefore, it is significant to match the rotation rate and welding speed to achieve the optimal combination of ELW and EST. So, the welding parameter used in the present work was optimized by previous trials.

\section{(2) The effect of pin length}

As one of the main factors that affect the material flow in the SZ, the stir pin plays a vital role in the joint formation during lap welding. As shown in Fig. 11, the interface is easy to break on the AS for severe plastic deformation. Then, the plastic material flowed downwards from the edge of the pin along the vertical direction and reflowed upwards along the outer side. Thus, the hook defect was formed. Meanwhile, the cold lap or voids could be produced near the RS for small deformation along the vertical direction [35]. It should be noted that the size of hook and cold lap formed in the lap FSW of steels is usually smaller than that of aluminum alloys due to less material flow.

For the joint with short pin length (inserted depth of $0.2 \mathrm{~mm}$, as shown in Fig. 11a), strong metallurgical bonding was hard to achieve with insufficient material flow at the interface. As shown in zone c (Fig. 9a), only limited ELW was achieved on the AS. With the increased pin length (inserted depth of $0.4 \mathrm{~mm}$, Fig. 11b), the ELW was significantly enlarged, and the bonding strength of interface was increased, resulting in changed failure mode from shear fracture to tensile fracture. When the pin was too long (inserted depth of $0.8 \mathrm{~mm}$, Fig. 11c), the feeble material deformation and flow on the bottom of the stir pin caused the formation of voids defect. As a result, unstable joint strength could be observed in Fig. 7.
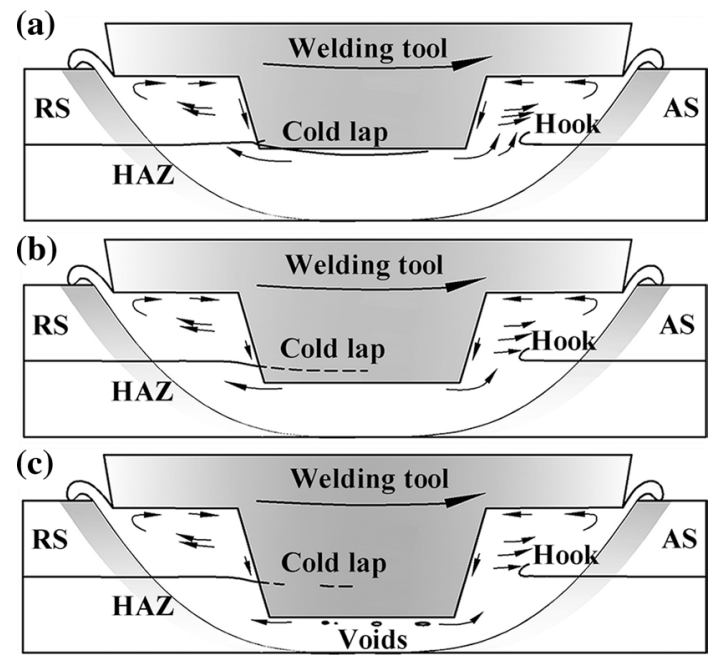

Fig. 11 Material flow model during FSW process of a $0.2 \mathrm{~mm}, \mathbf{b}$ $0.4 \mathrm{~mm}, \mathbf{c} 0.8 \mathrm{~mm}$ inserted depth joints

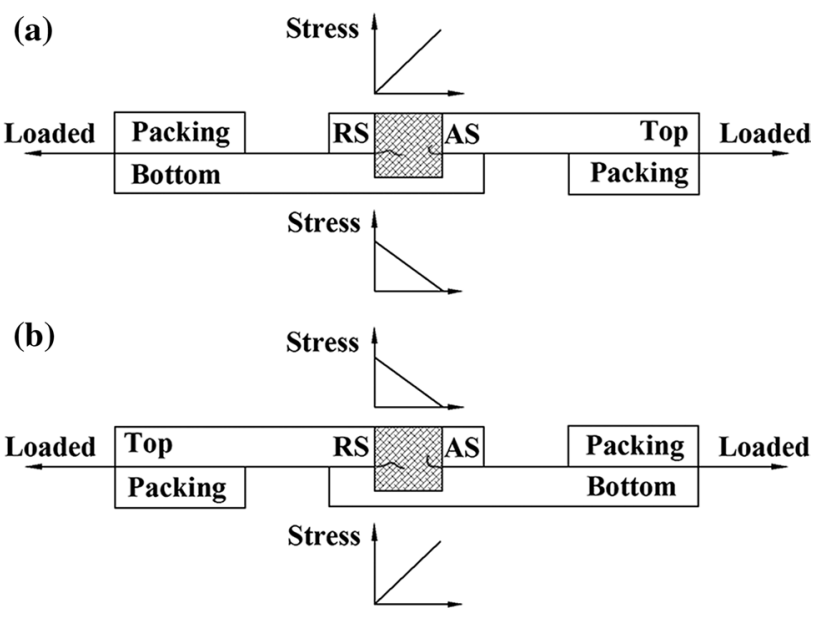

Fig. 12 Stress distribution in two kinds of tensile shear specimens: a AS-loaded, b RS-loaded

(3) The influence of joint loading mode

As illustrated in Fig. 12, the stress distribution characteristics of the AS-loaded and RS-loaded joints are different [36]. For the AS-loaded joint (Fig. 12a), the AS of the upper sheet and the RS of lower sheet undertake the maximum stress. In this case, the tip of hook was more likely to induce stress concentration and crack propagation, so most of these samples failed along hook (Fig. 8b). It should be noted that the crack in $0.2 \mathrm{AS}$-loaded sample was more likely to expand along the interface than hook for the weaker bonding strength of interface, so it failed preferentially along the interface between two sheets. The RSloaded joint (Fig. 12b) failed at the location of EST which undertook the highest stress during tensile test caused by thickness reduction and forming of cold lap (Fig. 8d-f). 
(4) The influence of surface quality of weld

The joint strength can be affected by the forming quality of weld surface which is related to the EST. It can be seen from Figs. 7 and 8 that the welds with smoother surface (inserted depth of $0.2 \mathrm{~mm}$ and $0.4 \mathrm{~mm}$ ) generally exhibited higher joint strength than those with the poor surface forming one (inserted depth of $0.8 \mathrm{~mm}$ ). Poor surface quality not only reduced the tensile shear strength, but also reduced the performance stability of the lap joint (such as 0.8 RS-loaded specimen).

\section{Conclusions}

In this work, friction stir welding of a DP1180 AUHSS was successfully carried out by using welding tools with three different pin lengths. Several conclusions can be drawn as follows:

1 Lap joints with good surface quality were obtained when the inserted depth was $0.2 \mathrm{~mm}$ and $0.4 \mathrm{~mm}$. Excessive inserted depth resulted in severe weld surface defects and inferior joint performance. Inconspicuous hook and cold lap defects with different sizes could be produced under all parameters. The cold lap tended to be alleviated with increasing the pin length.

2 The peak temperature in the SZs under all welding parameters reached above $A_{\mathrm{c} 3}$, and martensite phases with similar morphologies were formed. Large numbers of carbide particles were precipitated in martensite by the effect of self-tempering. It produced tough SZs with similar microhardness in comparison to the PM.

3 In the HAZ, the gradient-distributed temperature resulted in different types of microstructural changes. The generation of soft ferrite and tempering of martensite were the main reasons for the decreased hardness in this region. The recrystallization and/or phase transformations controlled the structural characteristics in different subregions of the HAZ.

4 The main factors affecting the mechanical properties of joints are welding parameter, pin length, joint loading mode and surface quality of weld. When the stir pin was inserted into the lower sheet at a depth of $0.4 \mathrm{~mm}$, the lap joint with optimal quality exhibited the highest tensile strength of $12.4 \mathrm{kN}$. The strength of AS-loaded joint was generally lower than that of the RS-loaded one for the effect of inducing cracking of hook.

Acknowledgements This work was supported by the National Natural Science Foundation of China (Nos. 51671190, 51774085 and 51471171).

\section{References}

[1] H.T. Jiang, D. Tang, Z.L. Mi, J. Iron Steel Res. 19, 1 (2007)

[2] J. Galan, L. Samek, P. Verleysen, K. Verbeken, Y. Houbaert, Rev. Metal. Madrid. 48, 118 (2012)

[3] Y.H. Rong, Acta Metall. Sin. 47, 1483 (2011)

[4] F.B. Yang, B.Z. Bai, D.Y. Liu, K.D. Chang, D.Y. Wei, H.S. Fang, Acta Metall. Sin. 40, 296 (2004)

[5] J.F. Wang, L.J. Yang, M.S. Sun, T. Liu, H. Li, Mater. Des. 97, 118 (2016)

[6] S. Daneshpour, S. Riekehr, M. Kocak, C.H.J. Gerritsen, Sci. Technol. Weld. Join. 14, 20 (2009)

[7] J. Jia, S.L. Yang, W.Y. Ni, J.Y. Bai, J. Mater. Res. 29, 2565 (2014)

[8] M.I. Khan, M.L. Kuntz, P. Su, A. Gerlich, T. North, Y. Zhou, Sci. Technol. Weld. Join. 12, 175 (2007)

[9] M. Pouranvari, S.P.H. Marashi, D.S. Safanama, Mater. Sci. Eng. A 528, 8344 (2011)

[10] R.S. Mishra, Z.Y. Ma, Mater. Sci. Eng. R 50, 1 (2005)

[11] P. Xue, X.X. Zhang, L.H. Wu, Z.Y. Ma, Acta Metall. Sin. 52, 1222 (2016)

[12] Z.Y. Ma, Q. Shang, D.R. Ni, B.L. Xiao, Acta Metall. Sin. 54, 1597 (2018)

[13] Q. Shang, D.R. Ni, P. Xue, B.L. Xiao, Z.Y. Ma, Mater. Sci. Eng. A 707, 426 (2017)

[14] G.Q. Wang, Y.H. Zhao, Y.F. Hao, J. Mater. Sci. Technol. 34, 73 (2018)

[15] X.H. Zeng, P. Xue, D. Wang, D.R. Ni, B.L. Xiao, Z.Y. Ma, Sci. Technol. Weld. Join. 23, 478 (2018)

[16] F.C. Liu, Y. Hovanski, M.P. Miles, C.D. Sorensen, T.W. Nelson, J. Mater. Sci. Technol. 34, 39 (2018)

[17] S. Mironov, Y.S. Sato, H. Kokawa, J. Mater. Sci. Technol. 34, 58 (2018)

[18] L.H. Wu, X.B. Hu, X.X. Zhang, Y.Z. Li, Z.Y. Ma, X.L. Ma, B.L. Xiao, Acta Mater. 166, 371 (2019)

[19] H. Zhang, D. Wang, P. Xue, L.H. Wu, D.R. Ni, B.L. Xiao, Z.Y. Ma, J. Mater. Sci. Technol. 34, 2183 (2018)

[20] M. Ghosh, K. Kumar, R.S. Mishra, Mater. Sci. Eng. A 528, 8111 (2011)

[21] M. Ghosh, K. Kumar, R.S. Mishra, Scr. Mater. 63, 851 (2010)

[22] S. Mironov, Y.S. Sato, S. Yoneyama, H. Kokawa, H.T. Fujii, S. Hirano, Mater. Sci. Eng. A 717, 26 (2018)

[23] M.M.Z. Ahmed, E. Ahmed, A.S. Hamada, S.A. Khodir, M.M. El-Sayed Seleman, B.P. Wynne, Mater. Des. 91, 378 (2016)

[24] M. Matsushita, Y. Kitani, R. Ikeda, M. Ono, H. Fujii, Y.D. Chung, Sci. Technol. Weld. Join. 16, 181 (2011)

[25] S.A. Khodir, Y. Morisada, R. Ueji, H. Fujii, Mater. Sci. Eng. A 558, $572(2012)$

[26] Q.F. Dai, R.B. Song, W.Y. Fan, Z.F. Guo, X.X. Guan, Acta Metall. Sin. 48, 1160 (2012)

[27] Q.L. Cui, D. Parkes, D. Westerbaan, S.S. Nayak, Y. Zhou, D. Liu, F. Goodwin, S. Bhole, D.L. Chen, Mater. Des. 90, 516 (2016)

[28] Z.W. Li, Y.M. Yue, S.D. Ji, P. Chai, Z.L. Zhou, Mater. Des. 90, 238 (2016)

[29] J. Trzaska, L.A. Dobrzański, J. Mater. Process. Technol. 192-193, 504 (2007)

[30] Z.Q. Cui, B.X. Liu, Metallurgy and Heat Treatment Theory, 3rd edn. (Harbin Institute of Technology Press, Harbin, 2007), p. 215

[31] W. Guo, Z.D. Wan, P. Peng, Q. Jia, G.S. Zou, Y. Peng, J. Mater. Process. Technol. 256, 229 (2018)

[32] X.D. Liu, Y.B. Xu, R.D.K. Misra, F. Peng, Y. Wang, Y.B. Du, J. Mater. Process. Technol. 263, 186 (2019)

[33] C. Luo, Y. Cao, Y. Zhao, L. Zhao, J. Shan, Weld. J. 97, 214 (2018)

[34] Y.M. Yue, Z.L. Zhou, S.D. Ji, J. Zhang, Z.W. Li, Int. J. Adv. Manuf. Technol. 89, 1691 (2017)

[35] H.J. Liu, Y.Q. Zhao, Y.Y. Hu, S.X. Chen, Z. Lin, Int. J. Adv. Manuf. Technol. 78, 1415 (2015)

[36] L. Cederqvist, A.P. Reynolds, Weld. J. 80, 281 (2001) 